\title{
Sexual Harassment, Self Esteem and Academic Engagement as Predictors of Academic Success of Female Secondary School Students
}

\author{
Baye Mekuriaw Ayenew $^{1}$ and Tilahun Gidey Gebremeskal ${ }^{2^{*}}$ \\ ${ }^{1}$ North Gondar Education Office, Post Box No: 428, Gondar, Ethiopia \\ ${ }^{2}$ Faculty of Educational and Behavioral Sciences, Bahir Dar University, Post Box No: 1876, \\ Bahir Dar, Ethiopia
}

\begin{abstract}
The purpose of the present study was to investigate the extent to which sexual harassment, selfesteem, and academic engagement predict academic success of female secondary school students in Gondar city. Correlational design was employed to answer the research questions raised. Respondents were 366 female secondary school students selected using multistage random sampling technique from three secondary schools. Data were gathered through questionnaires and document review. Sexual harassment, self-esteem, and academic engagement scales were used to collect data on the predictor variables while documents were reviewed to fetch data on respondents' academic performance as a proxy for academic success. Pearson Product Moment Correlation Coefficient, Multiple Linear Regression and Structural Equation Modeling - Path analysis were used to analyze data. Zero order correlation results indicated that all the variables treated in the study have statistically significant relationships to one another (at $P=0.01$ ). Multiple linear regression results revealed that all of the predictor variables had a statistically significant effect on the outcome variable-academic success. The path analysis on the other hand showed that the predictor variables had both direct and indirect impacts on the outcome variable with academic engagement having the strongest contribution $(\beta=0.68)$. It was concluded that sexual harassment, self-esteem, and academic engagement are important precursors of academic success of female secondary school students. Drawing on the results of the study several recommendations were forwarded among which offering orientation on sexual harassment and its consequences to members of school community and aligning learning experiences and assessment to academic engagement are some.

Copyright@2014 STAR Journal. All Rights Reserved.

Article Information Article History:

Received : 01-03-2014

Revised : 12-06-2014

Accepted : 14-06-2014

Keywords:

Sexual harassment

Self-esteem

Academic engagement

Academic success

*Corresponding Author:

Tilahun Gidey G

E-mail:

tilahung2000@gmail.com
\end{abstract}

\section{INTRODUCTION}

The constitution of the Federal Democratic Republic of Ethiopia (FDRE, 1995) under article 35, sub article 1 states about rights of women as follows: "Women shall, in the enjoyment of rights and protections provided for by this constitution, have equal right with men"p.154. Furthermore, the article under sub article 3 added: "The historical legacy of inequality and discrimination suffered by women in Ethiopia taken into account, women, in order to remedy this legacy, are entitled to affirmative measures. The purpose of such measures shall be to provide special attention to women so as to enable them compete and participate on the basis of equality with men in political, social and economic life as well as in public and private institutions." P.154. In line with this, Education and Training Policy (FDRE, 1994) also stipulated, "Special attention will be given to women and to those students who did not get educational opportunities in the preparation, distribution and use of educational support inputs"p.29.

Taking this into consideration improving educational access to girls, retaining them in school, reducing repetition rate and there by closing the gender gap was a major concern during the implementation of ESDP I, II and III (1997/8-2009/10) in Amhara region. To this effect, extensive awareness creation activities were undertaken on the importance of girls' education among communities. Efforts have been also made to make schools girls friendly through constructing separate latrine for girls and boys, promoting girls support system in schools, strengthening the capacity of educational personnel at all levels, and encouraging multi -sectoral approaches (involving convergence of sectoral intervention such as WASH program, HIV/ ADIS, School feeding etc. Moreover, girls" clubs were established in schools and tutorial, guidance and counseling services were provided to female students'. Gender mainstreaming guidelines and female education strategy have been developed. Amhara Female Education Forum has been also established and strengthened to monitor and evaluate the implementation of policies, strategies and guidelines on girls' education. All these endeavors have contributed to the significant increase in girls' enrollment in secondary education program. The GER for girls increased from 21.1 percent in 2005/2006 to 35.6 percent in 2009/2010, an increase of 13.8 percentage point in five years. 
Despite all the efforts particularly in recent years, the education system still remains inadequate to fulfill the education needs of girls all over the Amhara National Regional State. An assessment of girls education over five years period has identified girls access to education, participation, school attendance, academic achievement, and low internal efficiency to be major problems of girls' education in secondary education (AREB, 2010).

In a study which focuses on National Learning Assessment of grade 10 and 12 students it was reported that girls demonstrated lower academic performance. In all subjects in both grades 10 and 12, boys performed better than girls and the differences were significant in all cases. In the national sample included were from grade 10, 3151 males and 2260 females and from grade 12 2017 males and 561 females. In grade 10 samples boys scored an average of $38.7 \%$ whereas girls had an average of $32.2 \%$. Similarly among grade 12 samples boys scored an average of $49.2 \%$ whereas girls had an average of $42.6 \%$ (National Agency for Examination, 2010). This study also revealed that in Amhara National State, the average score of boys in grade 10 was $40.3 \%$ whereas girls had $32.1 \%$. In grade 12 , the average score of boys in the region was $49.2 \%$ whereas girls had 40.9\%.P.36-37.

In North Gondar Administrative Zone, from 6366 male and 7855 female candidate students who took $10^{\text {th }}$ grade, national examination in 2010/2011, 4862(61.9\%) female students obtained 2 points and above which is a pass mark to join different public and private colleges while $4974(78.13 \%)$ male students obtained the same. From a total of 119 students who got 4 points, number of girls was only 6 . In this same year, number of $12^{\text {th }}$ grade candidates who sat for Higher Education Entrance Examination in North Gondar Administrative Zone was 1562 for males 965 for females, totaling 2527. From these candidates, only 857 female students could score 265 and above (which is a pass mark for both sexes) while the number of boys who scored 265 and above was 1465. In Gondar city, 2011 males, 2017 females, totaling 4028 students took $10^{\text {th }}$ grade national examination in 2010/2011. From these candidates, only 901 female students could score 2 points and above, while number of male students who scored 2 points and above was 1269. The total number of students who scored 4 points was 65 among which only 11 were females. In this same year, in Gondar 691 male, 631 females, total 1322 grade 12 students took higher education entrance examination. From all these candidates, 649 male, 498 female students scored 265 points and above which was a pass mark for both male and female students.

All the above figures indicate that female students' academic achievement is inferior to males. This has to be taken as a serious problem and further studies have to be undertaken, while this study can help as a spring board. A host of in-school and out of school factors may be responsible for the lower academic performance of girls. In school factors may include the school climate, teachers' quality, and the learning experiences in class, the nature of assessment while out of school factors may include student characteristics including motivation, self-efficacy, self-esteem, ability, amount of school engagement and home characteristics. In this study however treated are sexual harassment (which is related to level of school safety), student self esteem, and academic engagement as precursors of academic performance of girls.

Females encounter sexual harassment in many different forms and cross-sectional evidence suggests that sexual harassment is relatively more detrimental for females in terms of negative behavioral, emotional, and educational outcomes (Hand and Sanchez, 2000) warranting more focus on sexual harassment sustained by females. Though there can be no universal definition, definitions of sexual harassment agree on the issue that sexual harassment is improper behavior that has a sexual dimension (O'Donohue, Downs and Yeater, 1999, p. 112). Authors of the present study conceptualize sexual harassment as unwanted sexual attention. Sexual harassment can occur anywhere including female students' way to and back from school. There are evidences that walking long distance every day to school may expose girls to sexual threats or physical attack (Leach et al. 2003 cited in Jacobs and wet, 2011). Thus the amount of time it takes female students from home to school can determine the rate at which they will be harassed sexually.

Though there are competing theories on sexual harassment, its impacts remain. In schools, men devalue women by calling attention to their sexuality. This will eventually erode their self esteem. In one study (Kopels and Dupel, 1999) females that have been sexually harassed have reported experiencing embarrassment," feeling self-conscious, feeling less sure or less confident of themselves following sexual harassment. Self-esteem refers to an individual's overall view of himself or herself. Self-esteem also is referred to as self-worth or self-image (Santrock, 2009:92). When self-esteem is high, a student is motivated to achieve (Harter, 1990 cited in Papalia, 1998). On the other hand, students whose self-esteem is contingent on success may view failure as an indictment of their worth and feel helpless to do better (Papalia, 1998). If they feel helpless to do better, it is clear that their academic achievement is influenced negatively. Therefore, to improve students' academic achievements, raising their self-esteem should be considered as a factor.

Equally important as self-esteem to the academic performance of female students is academic engagement. Academic engagement is students' psychological investment in, and effort directed toward learning, understanding, or mastering the knowledge, skills, or crafts that academic work is intended to promote (Newmann, Wehlage, and Lamborn, 1992:12). Studies have shown that engagement of students contributes to academic performance (Suárez-Orozco, Pimentel, and Martin, 2009; Fredricks, Blumenfeld, and Paris, 2004; Greenwood, Horton, and Utley, 2002; Marks, 2000; National Research Council, 2004). Academic engagement can be affected by self-esteem of students. This is because it is when students have beliefs in themselves that they will think their activities will lead to better academic achievements. Hence those who believe in themselves are more likely to engage academically. There are research evidences supporting this (see Connell, Spencer, and Aber, 1994 for example).

This study is believed to provide information for the sample secondary schools in Gondar city about the magnitude of female students' sexual harassment, levels of self-esteem and the extent of school engagement of 
female students; which in turn can help to improve female students' academic achievement. It also helps as a point of departure in suggesting for the formation of future policies and rules that prohibit sexual harassment and create positive school environments of secondary schools which is conducive for female students learning. It can also help female secondary school students to take precautionary measures that will help improve their academic performances.

Some local studies have been conducted to examine the rates, the antecedents of sexual harassment and academic impacts of sexual harassment (for example, Tibebe, 2009). But to the best knowledge of the researchers no study has examined the complex relationships of sexual harassment, self-esteem and level of academic engagement in predicting academic success of female students. This study thus explores the effects of sexual harassment on students' self-esteem and school engagement and the combined influences of these variables on academic success of female students. Based on these, the study will give answers to the following basic questions. Are there significant relationships among the predictor variables? What is the combined effect level of sexual harassment, self esteem and academic engagement on students' academic success? Which variables significantly predict the academic success of students? Is the effect of distance from the school as an exogenous variable on students' academic success moderated by sexual harassment, self esteem and academic engagement?

To test the direct and indirect effects of the independent (predicator) variables on the dependent variable (academic success as represented by mean semester score), the present study based on literature and empirical findings developed a model that shows the effects of exogenous variables and those mediating variables on the outcome variable. Here under is the model developed.

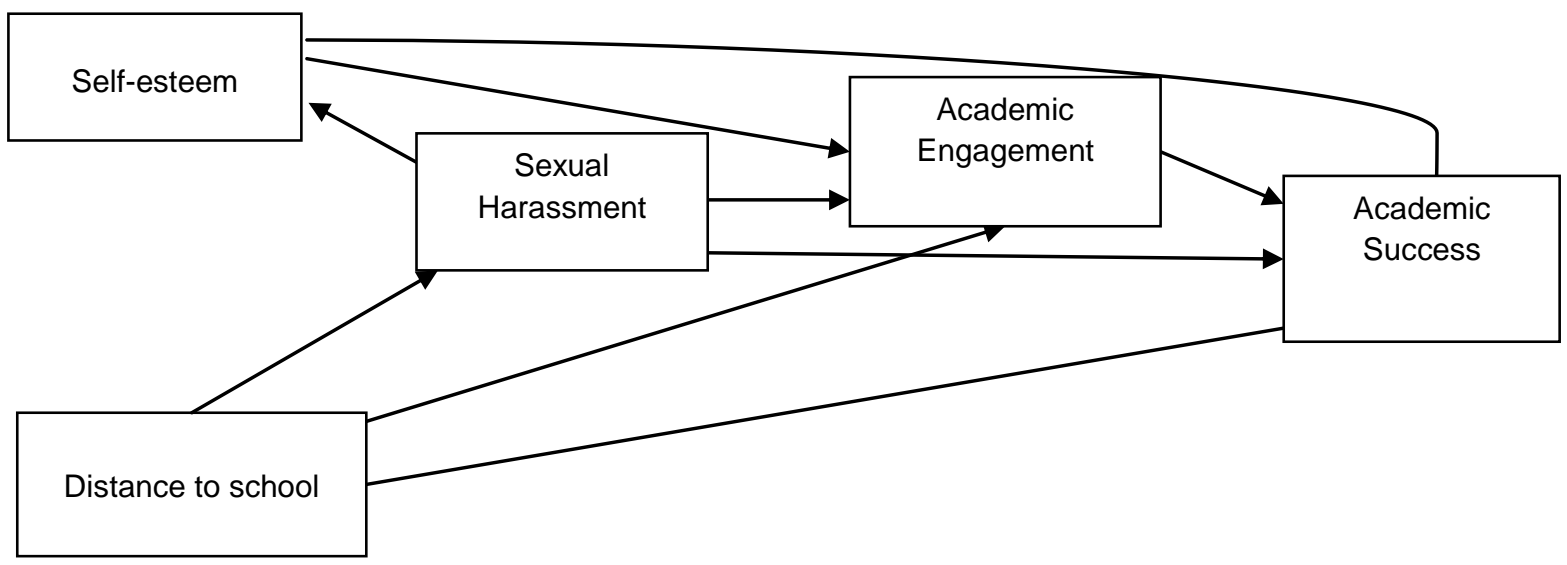

Figure 1: A path model proposed to test the effect of distance from the school as exogenous variable on students' academic success moderated by sexual harassment, self esteem and academic engagement

\section{MATERIALS AND METHODS}

\section{Population, Samples and Sampling Techniques}

The study was conducted in Gondar city secondary schools. In the city, there are six private and six public general secondary schools and one public preparatory school. From the six general public secondary schools, two of them are full cycle (9-12). From the total available thirteen secondary schools, the population of the study was only the female students from seven public secondary schools among which one is preparatory school

Concerning school sampling, from six general secondary schools, two schools were selected randomly. The preparatory school was taken by using availability sampling since it is the only second cycle secondary school available in the city. Therefore, in the sample are female students of three secondary schools. With respect to sample students, all students from randomly selected sections ( 1 from each grade level of 9 and 10 from each school) were taken. Similarly in the case of the preparatory school, all female students of two sections from each grade level, one from social sciences and another one from natural sciences stream were included into the sample. Finally, a total sample of 366 female students were used in the study.

\section{Data Gathering Instruments}

Sexual Harassment Questionnaire: This questionnaire has 7 items which are closed ended. The items were adapted from the work of Chiodo, Wolfe, Crooks, Hughes, and Jaffe (2009). These items ask female students the extent to which they have encountered different forms of sexual harassment from male students in the last two years. The items had options always/often scored 4 , sometimes scored 3 , rarely scored 2 , and never scored 1 .

Self-Esteem Questionnaire: The Rosenberg (1965) selfesteem questionnaire was taken from Rosenberg (1979) to be used as a measure of global self-esteem.. The Rosenberg Self-Esteem Scale was selected because it is the most widely-used self-esteem measure in social science research (Vialle, Heaven, and Ciarrochi, 2005). The questionnaire has 10 close ended items. The options for the items were 'strongly agree', 'agree', 'disagree' and 'strongly disagree' which were scored $4,3,2$, and 1 respectively.

Academic Engagement Questionnaire: The number of items for school engagement was 27 which were adapted from the work of Finlay (2006). The items had options always/often scored 4 , sometimes scored 3 , rarely scored 2 , and never scored 1. 
First semester mean score of students was used to measure academic success. To fetch this data the academic records obtained from the archives were consulted

\section{Pilot Test}

All the data gathering instruments were tested on 43 female students on a school that was not included in the final study. Using Cronbach alpha it was found out that sexual harassment scale had a reliability of $\alpha=0.78$, selfesteem $\alpha=0.82$, and academic engagement $\alpha=0.85$. This indicates that the scales had a very good reliability and could be used in the final data collection process.

\section{Data Gathering Procedures}

After preparing all data gathering tools, experts' comments and pilot tests were made to give the tools final shape. Official letters for the 3 sample schools were written to secure collaboration in the course of data collection. The purpose of the study was made clear to the schools. Orientation on the purpose and importance of the study was given to all female students in sample schools. Then the questionnaires were administered with the help of three teacher assistants from the three sample schools. These teachers were oriented on how each respondent should complete the items.

\section{Data Analysis Techniques}

The data collected were analyzed and interpreted quantitatively. To examine the interrelationships among all the variables treated Pearson Product Moment Correlation Coefficient was used. Whereas, multiple linear regression was employed to determine the effect of the independent variables on the dependent variable (academic performance). To examine the direct and indirect effects of the independent variables structural equation modeling, particularly path analysis was conducted with AMOS for windows version 20. All significance testes were set at $\alpha=0.01$.

\section{RESULTS}

One of the objectives of this study was to determine the relationships among each of the variables treated in the study. Thus, to have an overview of the relationships among each of the variables treated, Pearson Product Moment Correlation Coefficients were determined. The results are displayed in Table 1.

Table 1: Inter-correlation matrix for distance to school, sexual harassment, self esteem, academic engagement, and academic success

\begin{tabular}{lllllll}
\hline & Variables & $\mathbf{1}$ & $\mathbf{2}$ & $\mathbf{3}$ & $\mathbf{4}$ & $\mathbf{5}$ \\
\hline 1. & Distance to school & 1.000 & & & & \\
2. Sexual Harassment & $0.414^{*}$ & 1.000 & & & \\
3. Self-esteem & $-0.378^{*}$ & $-0.829^{*}$ & 1.000 & & \\
4. Academic engagement & $-0.388^{*}$ & $-0.833^{*}$ & $0.902^{*}$ & 1.000 & \\
5. Academic Success & $-0.414^{*}$ & $-0.899^{*}$ & $0.894^{*}$ & $0.912^{*}$ & 1.000 \\
\hline
\end{tabular}

From the Table, it can be learned that sexual harassment correlated negatively and significantly with self-esteem, academic engagement and academic success. This signifies students who have higher experiences of sexual harassment tend to have lower self esteem, engage less academically and demonstrate lower levels of academic success. In the table we can also see that self-esteem correlated positively and significantly with measures of academic engagement and academic success. This means students with higher levels of selfesteem are more likely to engage more academically and demonstrate higher academic success while vice versa is true. Likewise, academic engagement was found to positively and significantly correlate with academic success denoting that students with higher levels of academic engagement are more likely to be academically more successful.

Apart from examining the intercorrelations among the variables treated, the present study had the purpose of determining the combined effect of sexual harassment, self-esteem, and academic engagement on academic success. For this purpose multiple linear regression was conducted. Specifically the intention was to determine the strength of the overall contribution of the predicator variables (namely distance to school, sexual harassment, self-esteem, and academic engagement) to the dependent variable, and to identify those independent variables that best explained the variances in the academic success of students. The results show that the combined effect of all the independent variables on the dependent variable was statistically significant $(R=.950$, $\left.\mathrm{R}^{2}=0.903, \mathrm{~F}_{4}, 361=841.898 ; \mathrm{P}<0.001\right)$. This means the independent variables together explained about $90.3 \%$ of the variance in academic success of students. The independent contributions of each predicator variable to the dependent variable were also determined. Table 2 shows the results.

Table 2: Regression of CGPA on distance to school, sexual harassment, self esteem, and academic engagement

\begin{tabular}{|c|c|c|c|c|}
\hline \multirow{2}{*}{ Variable } & \multicolumn{3}{|c|}{ Unstandardized CoefficientsStandardized Coefficients } & \multirow{2}{*}{$\mathbf{t}$} \\
\hline & B & Std. Error & Beta & \\
\hline Distance to school & -0.014 & 0.012 & -0.022 & -1.237 \\
\hline Sexual Harassment & -0.888 & 0.072 & -0.393 & $-12.394^{*}$ \\
\hline Self-esteem & 0.507 & 0.096 & 0.211 & $5.253^{*}$ \\
\hline Academic Engagement & 0.361 & 0.038 & 0.386 & $9.504^{*}$ \\
\hline
\end{tabular}


From Table 2, it can be learned that while sexual harassment, self esteem and academic engagement had statistically significant effects on academic success of students the effect of distance to school was not statistically significant. To determine the extent of increase of the overall $R^{2}$ made by the inclusion of each of the independent variables into the equation, stepwise multiple linear regression was run. Table 3 shows the results.

Table 3: Stepwise multiple regression of academic Success on the independent variables treated

\begin{tabular}{|c|c|c|c|c|c|c|c|}
\hline \multirow[t]{2}{*}{ Model } & \multirow[t]{2}{*}{ Variables Entered } & \multicolumn{2}{|c|}{$\begin{array}{c}\text { Unstandardized } \\
\text { Coefficients }\end{array}$} & \multirow{2}{*}{$\begin{array}{c}\begin{array}{c}\text { Standardized } \\
\text { Coefficients }\end{array} \\
\text { Beta }\end{array}$} & \multirow[t]{2}{*}{$\mathbf{R}^{2}$} & \multirow[t]{2}{*}{$\Delta \mathbf{R}^{2}$} & \multirow{2}{*}{$F\left(\Delta \mathbf{R}^{2}\right)$} \\
\hline & & $\mathbf{B}$ & Std. Error & & & & \\
\hline 1 & Academic Engagement & 0.852 & 0.020 & 0.912 & 0.832 & 0.832 & $1808.206^{*}$ \\
\hline \multirow{2}{*}{2} & Academic Engagement & 0.500 & 0.029 & 0.535 & \multirow{2}{*}{0.895} & \multirow{2}{*}{0.063} & \multirow{2}{*}{$218.082^{*}$} \\
\hline & Sexual Harassment & -1.023 & 0.069 & -0.453 & & & \\
\hline \multirow{3}{*}{3} & Academic Engagement & 0.363 & 0.038 & 0.389 & \multirow{3}{*}{0.902} & \multirow{3}{*}{0.007} & \multirow{3}{*}{$27.744^{*}$} \\
\hline & Sexual Harassment & -0.903 & 0.071 & -0.399 & & & \\
\hline & Self-esteem & 0.509 & 0.097 & 0.212 & & & \\
\hline
\end{tabular}

Table 3 indicates important variables that significantly predicted academic success. The variables were academic engagement, sexual harassment, and self esteem. The table indicates that academic engagement alone explained $83.2 \%$ of the variance in academic success, which was statistically significant $\left(F_{1}, 364=\right.$ 1808.206, $p<0.01$ ). The inclusion of sexual harassment in the equation improved the coefficient of determination by $6.3 \%$, which was a significant raise $\left(F_{1,363}=218.082\right.$; $P<0.01)$. At last when self-esteem was added to the equation the coefficient of determination increased by 0.7 $\%$, which was a statistically significant increase as well $\left(\mathrm{F}_{1,362}=27.744 ; P<0.01\right)$.

The other task of this study was to examine the direct and indirect effects of the variables on academic success. To do this a path model was run and the results are presented in Figure 2. This path model tests the fit between the data and the path model presented in figure 1.

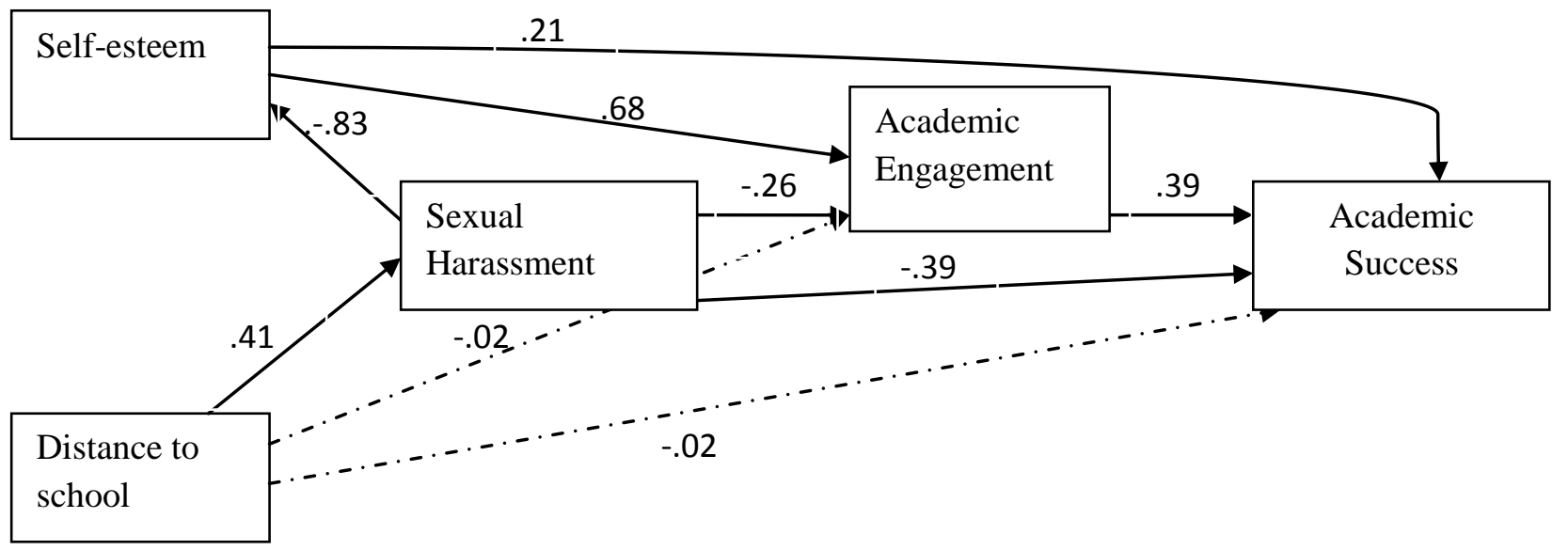

Figure 2: The results of the paths for the proposed model (The dotted lines represented effects that were not significant at $\alpha=0.01$ )

Using Amos 20, the specified model was tested to see whether it fits the data or not. Results indicated that the model fits the data very well as reflected in the fit indices: $\chi^{2}=1.73, \mathrm{df}=1, \mathrm{p}=0.188, \mathrm{CFI}=1.000, \mathrm{NFI}=0.999$,
$\mathrm{RFI}=0.991$, and $\mathrm{RMSEA}=0.045, \mathrm{p}>0.05$. However, to create a model that is more parsimonious, paths that were not statistically significant were dropped and the model was rerun. Figure 3 shows the results of the new model.

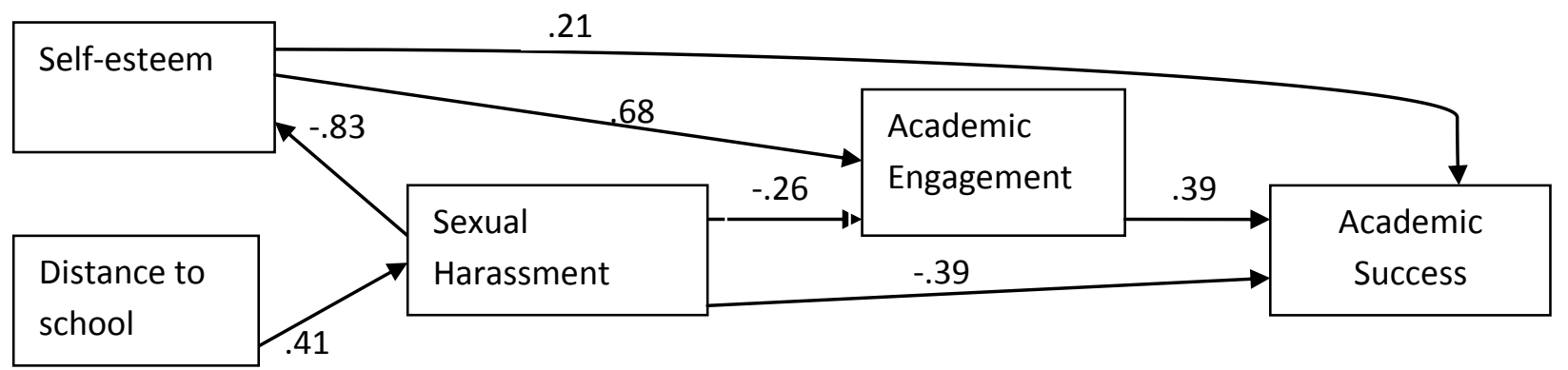

Figure 3: The last version of the path model that represented the effects of distance to school, sexual harassment, selfesteem and engagement on academic success of students 
The model that was rerun and indicated in figure 3 revealed that it fits the data very well as reflected in the fit indices: $\chi^{2}=4.279$, df $=3, p=0.233, C F I=0.999$, NFI $=0.998, \mathrm{RFI}=0.993$, and RMSEA $=0.034, P>0.05$.

The effects of the predictor variables on the criterion variables were significant and in the anticipated direction. The results indicated that girls who travel a long distance to their schools encounter sexual harassment more than those who travel shorter distances to school $(\beta=.41)$. Quite interesting is the strength of the effect of sexual harassment on self esteem $(\beta=-0.83)$ and that of self esteem on academic engagement $(\beta=0.68)$ which in turn significantly predicts academic success $(\beta=0.39)$. Sexual harassment is found to significantly predict both academic engagement and academic achievement. The direct and indirect effects of predictor variables on criterion variables were also examined. Table 4 shows the results.

Table 4: Direct, indirect, and total effects of the variables on academic success of students (standardized coefficients)

\begin{tabular}{cccc}
\hline Variables & $\begin{array}{c}\text { Direct } \\
\text { effects }(\beta)\end{array}$ & $\begin{array}{c}\text { Indirect } \\
\text { effects }\end{array}$ & $\begin{array}{c}\text { Total } \\
\text { effects }\end{array}$ \\
\hline Distance to school & .00 & $-.372^{*}$ & $-.372^{*}$ \\
Sexual harassment & $-.399^{*}$ & $-.499^{*}$ & $-.899^{*}$ \\
Self-esteem & $.212^{*}$ & $.264^{*}$ & $.475^{*}$ \\
Academic engagement & $.389^{*}$ & .000 & .389 \\
\hline & ${ }^{*} P<0.01$ & &
\end{tabular}

As presented in Table 4, except distance to school all the predictor variables have significant direct effect on academic success of students. Examination of the indirect effects on the other hand reveals all the predictors significantly affect the criterion variable, academic success.

The model also revealed that the combined contributions of the covariates to the variance in academic success of students was $90.3 \%$ which is very interesting. When we examine the effects of distance to school, sexual harassment, and self-esteem on academic engagement, they jointly accounted for $83.7 \%$ of its variance. On the other hand $68.7 \%$ of the variance in self esteem is accounted for by the joint effect of distance to school and sexual harassment. And it is $17.1 \%$ of the variance in sexual harassment that could be accounted for by distance to school.

\section{DISCUSSION}

The major purpose of the present study was to determine the relationships of sexual harassment, selfesteem, academic engagement and academic success. Zero-order correlation tests, multiple linear regression and structural equation modeling using path model were employed. The correlational analysis results indicated that sexual harassment related with self-esteem, academic engagement and academic success. This result goes in line with previous findings such as Kopels and Dupper (1999), Mumen and Smolak (2000).

Self-esteem had higher correlation with the rest of the variables treated in the study. A large body of research goes in line with this result. For example, Lee, Croninger, Linn and Chen (1996) reported a significant association of self-esteem with academic engagement and academic performance. Other studies had obtained a significant association between self-esteem and academic engagement (Connell, Spencer, and Aber, 1994; Skinner, Wellborn, and Connell (1990). The association between self-esteem and academic achievement is well documented (Baumeister, Campbell, Krueger, and Vohs, 2003; Klein and Keller, 1990).The present study's claim of a positive association between academic engagement and academic success has a strong research support also (Fredricks, Blumenfeld and paris, 2004: Marks, 2000; Voelkl, 1997).

From the path analysis it was found out that sexual harassment has a negative and significant impact on selfesteem. In fact this was found to be the strongest impact sexual harassment has $(\beta=0.83)$. In a similar vein in Kopels and Dupper's (1999) study it was found out that among the study participants $64 \%$ of girls reported experiencing "embarrassment," $52 \%$ reported feeling "self-conscious," and 43\% reported feeling less sure or less confident of themselves as a result of sexual harassment. The other interesting finding from the path analysis was the impact sexual harassment has on both academic engagement and academic success.

In the path it was indicated that sexual harassment had a sizably strong impact on both academic engagement and academic success. Kopels and Dupper's(1999) study has reported similar findings. When female students are sexually harassed it is likely that they will not focus on their studies, engage less leading to poor school performance. In a study conducted by Lee Croninger, Linn and Chen (1996) involving secondary school students drawn from a wide range of public secondary schools respondents have mentioned talking in class less, paying less attention in class, finding it hard to study, and performing poorly in school to have resulted from experiences of sexual harassment they have sustained. Decreased productivity and performance, and decreased participation in school activities may occur as students must focus on, and strategize about, ways to deal with the harassment (David, 2010). By way of instilling unfavorable attitude toward school, sexually harassed girls may also disengage from school activities and perform poorly at school (Kopels and Dupper, 1999).

Another interesting finding that emerged from this study was the impact of self esteem on both academic engagement and academic success. The impact of self esteem on academic engagement was also documented in other studies (Connell, Spencer, and Aber, 1994 for example). This impact can be explicated by the fact that students may engage more in their academics when they have the belief on themselves and their actions. Thus when one has a belief on oneself, they engage more in their school activities based on their beliefs that their action will produce positive school outcomes. In contrast those students who have lower levels of self belief may not engage in school activities because they may not foresee the possible links between their level of engagement and academic success. The findings of the present study on self esteem and academic success is supported by previous studies (Colquhoun and Bourne, 2012 for example). But whether self esteem causes or the other way is not conclusive. Even though the issue of which comes first self-esteem or academic success is not yet resolved it is likely that a positive change in one 
facilitates a positive change in the other (Hamache,, 1985 cited in Dembo, 1997). There are hence arguments that the best way to improve students' achievement is to increase their self-esteem (Ruble et al. 2004 cited in Mohammed, 2010).

Further result revealed in the present study has been that academic engagement was the strongest predictor of and puts the strongest impact $(\beta=0.68)$ on academic success of students. This is in agreement with the findings of several previous researches (Alexander, Entwisle, and Dauber, 1993, Campbell, Voelkl, and O'Donahue, 1997 Fincham, Hokoda,and Sanders, 1989; Voelkl, 1997). Engagement should improve the academic performance of students. This is because engaged students may have wider opportunities to practice learning materials. These students are also characterized by positive school behaviors- showing a preference for challenging work, persisting in the face of failure, and having a more internal focus toward learning beyond the desire to just attain good grades (Fredricks et al., 2004; Patrick, Ryan, and Kaplan, 2007). Moreover, when students are seen engaged by their teachers they are likely to receive motivation from teachers (Skinner and Belmont, 1993) which normally results in better academic performance.

\section{CONCLUSIONS}

This study has indicated that the independent variables treated had significant effects on academic success of female students. When the rate of sexual harassment increases, self-esteem, academic engagement and academic success will suffer. This study has clearly indicated also that sexual harassment affects the academic performance of students both directly and indirectly through its impacts on self esteem and academic engagement. Higher levels of self esteem predict higher levels of academic engagement and improved school work. Thus, when students feel good about themselves, their engagement level increases and their academic performance improves. Among the variables treated in this study academic engagement turned to be the best predictor of academic success implying that the more students engage in school work the better their academic performance turns and the less students engage in school the poorer their academic performance will be.

This study has clearly indicated the impacts of all the independent variables treated in the study on academic achievement directly and through meditational variables. Based on the findings the researchers recommend raising public awareness among members of school community in enforcing sexual harassment policies at school level. The local community and parents should build strong link with secondary schools to help protect long distance travelling female students from sexual harassment. It is necessary that schools create conducive and safe environments in classrooms by involving subject teachers, homeroom teachers and students class representatives. Learning experiences as well as the nature of assessments should be arranged in a way they will engage students academically. Verbal interactions teachers make with students should not harm the selfesteem of students. Finally future studies should consider other group of perpetrators such as school personnel and the long-term psychological impacts of sexual harassment. This may include studies of depression, psychosomatic problems and irrational thoughts.

\section{REFERENCES}

Alexander, K.L., Entwisle, D.R., and Dauber, S.L. (1993). First-grade classroom behavior: Its short- and long-term consequences for school performance. Child Development 64: 801-814.

Amhara Education Sector Development Program (1907/82009/10).

Amhara National Regional State Education Bureau (2010). Annual Education Statistics Abstract. Unpublished.

Baumeister, R.F., Campbell, J.D., Krueger, J.I., and Vohs, K.D. (2003). Does high self-esteem cause better performance, interpersonal success, happiness, or healthier lifestyles? Psychological Science in the Public Interest 4(1): 1-44

Chiodo, D., Wolfe, D.A., Crooks, C., Hughes, R. and Jaffe, P. (2009). Impact of Sexual Harassment Victimization by Peers on Subsequent Adolescent Victimization and Adjustment: A Longitudinal Study. Journal of Adolescent Health 45: 246-252.

Colquhoun, L.K. and Bourne, P.A. (2012). Self-Esteem and Academic Performance of 4th Graders in two Elementary Schools in Kingston and St. Andrew, Jamaica. Asian Journal of Business Management 4(1): 36-57

Connell, J.P., Spencer, M.B., and Aber, J.L. (1994). Educational risk and resilience in African-American youth: Context, self, action, and outcomes in school. Child Development 65: 493-506

Dembo, M.H. (1994). Applying Educational Psychology. New York: Longman publishing group;

FDRE (1995). Constitution of the Federal Democratic Republic of Ethiopia- Addis Ababa.

Federal Democratic Republic of Ethiopia (1994). Education and Training Policy. Addis Ababa.

Fincham, F.D., Hokoda, A., and Sanders, R. (1989). Learned helplessness, test anxiety, and academic achievement: A longitudinal analysis. Child Development 60: 138-145

Finlay, K. (2006). Quantifying School Engagement: Research Report. National Center for School Engagement. Denver, CO.

Fredrick, J.A., Blumenfeld, P.C., and Paris, A.H. (2004). School engagement: potential of the concept, state of evidence. Review of Educational Research 74(1): 59-109.

Fredricks, J.A., Blumenfeld, P.C., and Paris, A.H. (2004). School engagement: Potential of the concept, state of the evidence. Review of Educational Research 74: 59-109.

Greenwood, C.R., Horton, B.T. and Utley, C.A. (2002). Academic engagement: Current perspectives in research and practice. School Psychology Review 31(3): 1-31

Hand, J. Z., and Sanchez, L. (2000). Badgering or bantering? Gender differences in experiences of, and reactions to, sexual harassment among U.S. high school students. Gender and Society 14: 718-746

Jakob, S. and Wet, C. (2011). A comparison between the consequences of peer sexual harassment for Boys and Girls. School of Education studies, University of Free State 28(1): 29-42.

Klein, J.D. and J. Keller (1990). Influence of Student Ability. Locus of control and type of instructional control performance and confidence. Journal of Education and Research 83(3): 140-146 
Baye Mekuriaw and Tilahun Gidey

Kopels, S. and Dupper, D.R. (1999). School-Based Peer Sexual Harassment. Child Welfare LXXVIH (4): 435-460

Lee, V.E., Croninger, R.G., Linn, E. and Chen, X. (1996). The Culture of Sexual Harassment in Secondary Schools. American Educational Research Journal 33(2): 383-417

Martin, J.L. (2007). Violence against women: peer sexual harassment: Finding voice, changing culture. An intervention strategy for adolescent females. Retrieved on Dec. 20, 2007 from http://vaw.Sagepub. Com/content/14 /1/100.ref S.htm

Mohammad, A. (2010). Relationship between self-esteem and academic achievement amongst pre-university students. Journal of Applied Sciences 10: 2474-2477.

Murnen, S.K. and Smolak, L. (2000). The Experience of Sexual Harassment Among Grade-School Students: Early Socialization of Female Subordination? Sex Roles: A Journal of Research 43(1-2): 1-17.

National Agency for Examinations (2010). Ethiopian First National Learning Assessment of Grade 10 and 12 Students. Addis Ababa.

National Research Council. (2004). Engaging schools: Fostering high school students' motivation to learn. Washington, DC: National Academies Press.

Newmann, F.M., Wehlage, G.G. and Lamborn, S.D. (1992). The significance and sources of student engagement in Newmann, F.M (ed). Student Engagement and Achievement in American Secondary Schools. Teachers' College Press, Columbia University: Newyork.

O'Donohue, W., Downs, K., and Yeater, E.-A. (1999). Isues of peer sexual harassment among teenagers.: A review of the literature. Aggression and Violent Behavior 3: 111-128

Papalia, D.E. and olds, S.W. (1998). Human development. ( $7^{\text {th }}$ ed.). New York: McGraw-HII,
Sci. Technol. Arts Res. J., April-June 2014, 3(2): 229-236

Patrick, H., Ryan, A. M., and Kaplan, A. (2007). Early adolescents' perceptions of the classroom social environment, motivational beliefs, and engagement. Journal of Educational Psychology 99: 83-98.

Rosenberg, M. (1979). Conceiving the self. Basic books. New York:

Santrock, I.W. (2011). Educational Psychology. (5 ${ }^{\text {th }}$ ed.).New York: The McGraw-Hill companies.

Skinner, E. A., Wellborn, J. G., and Connell, J. P. (1990). What it takes to do well in school and whether l've got it: A process model of perceived control and children's engagement and achievement in school. Journal of Educational Psychology 82: 22-32.

Skinner, E.A., and Belmont, M.J. (1993). Motivation in the class room. Reciprocal effects of teacher behavior and student engagement. Journal of Educational Psychology 85(4): 571-583.

Suárez-Orozco, C., Pimentel, A., Martin, M. (2009). The significance of relationships: Academic engagement and achievement among newcomer immigrant youth. Teachers College Record 111(3): 712-749.

Tibebe Kassahun (2009). Sexual harassment: the case of Jimma University. Unpublished MA thesis: Addis Ababa University.

Vialle, W., Heaven, P.C.L. and Parrochi, J. (2005) The relationship between self-esteem and academic achievement in high ability students: Evidence from the Wollongong Youth Study. The Australasian Journal of Gifted Education 14 (2): 39-45.

Voelkl, K. E. (1997). Identification with school. American Journal of Education 105: 294-318. 